\title{
Sensory stimuli associated with gestation and parturition evoke cardiac and behavioral responses in fetal rats
}

\author{
APRIL E. RONCA and JEFFREY R. ALBERTS \\ Indiana University, Bloomington, Indiana
}

\begin{abstract}
We examined the ability of late-gestation (Day 21) fetal rats to detect and respond to stimuli associated with gestation and parturition. Previous work in rats suggests that maternal behavior and physiology provide specific tactile, vestibular, and thermal stimuli to fetal and newborn offspring. For example, fetuses in utero are exposed to angular acceleration and vibration as the mother engages in exploratory behavior and self-grooming. Late-gestation fetuses are compressed by strong contractions of the uterus during parturition. Newly born pups are exposed to intense tactile stimulation associated with maternal licking and to prolonged extrauterine cooling during the immediate postpartum period. In the present study, we simulated five forms of biological stimuli normally associated with gestation and parturition. Using in vivo observation techniques in which fetuses were externalized from the dam's uterus, but retained an intact umbilical circulation, we measured cardiac and behavioral responses of Day 21 rat fetuses to stimulation. Each subject received a single 5-sec presentation of (1) angular acceleration, to mimic rearing of the pregnant dam, (2) vibration, to mimic hindlimb scratching of the dam, (3) mechanical compression, to mimic labor contractions, (4) stroking, to mimic postpartum licking, or (5) cooling, to mimic the thermal effects of birth. Fetal rats responded to each form of stimulation with bradycardia and behavioral activation. These findings provide evidence that fetal offspring can detect and respond to the classes and levels of biological stimuli that are normally associated with maternal behavior and physiology during perinatal life.
\end{abstract}

The prenatal environment contains chemical (Pederson \& Blass, 1982; Schaal, Orgeur, \& Rognon, in press; Tam \& Chan, 1977), cutaneous (Nathanielsz et al., 1985; Ronca, Lamkin, \& Alberts, 1993), vestibular (Previc, 1991; Ronca et al., 1993), acoustic (Armitage, Baldwin, \& Vince, 1980; Decasper \& Fifer, 1980; Gottlieb, 1987, 1988; Walker, Grimwade, \& Wood, 1971), and visual (Jacques, Weaver, \& Reppert, 1987a, 1987b) stimuli (see also Bradley \& Mistretta, 1975; Gottlieb, 1971). In mammals, prenatal sensory stimuli arise predominantly from the mother's behavior and physiology (Alberts \& Ronca, 1993; Ronca \& Alberts, in press; Ronca et al., 1993). Chemical by-products of the maternal diet and the fetus's own waste products effect chemosensory changes in amniotic fluid (Tam \& Chan, 1977; Schaal et al., in press). Vestibular and cutaneous stimuli are associated with maternal movements (Ronca et al., 1993). Other cutaneous stimuli are produced internally by contractures, mild episodic contractions of the pregnant uterus that antedate the onset of labor (Nathanielsz et al., 1985). During labor, additional vestibular and cutaneous stimuli

\footnotetext{
This research was supported by National Institute of Mental Health Grant MH46485 to J.R.A. and A.E.R. We wish to thank Regina Abel, Michael Armbruster, and Carrie Iwema for technical assistance. Illustrations were created by Jim Hull. Correspondence should be addressed to A. E. Ronca, Department of Psychology, Indiana University, Bloomington, IN 47405.
}

arise as the fetus is squeezed and pitched by the contracting uterus (Ronca et al., 1993), and maternal vocalizations can provide an auditory accompaniment to labor contractions (Vince, Billing, Baldwin, Toner, \& Weller, 1985). At birth, as the fetus is compressed through the relatively small space comprising the birth canal and delivered into a cold extrauterine environment, cutaneous, vestibular, and thermal stimuli become more intense (Ronca et al., 1993).

Remarkably little is known about the extent to which perinatal organisms are able to sense the stimuli present within their habitat. This is due, in part, to our limited understanding of sensory function in perinatal mammals. It is known, however, that auditory stimulation is detected by the fetus in utero (humans: Decasper \& Fifer, 1980; Decasper \& Spence, 1986; sheep: Vince, 1979; Vince, Armitage, Shillito-Walser, \& Reader, 1982) and that chemosensory cues within amniotic fluid are important for successful first nipple attachment (rat: Pederson \& Blass, 1982). These and other studies provide clear evidence that certain stimuli present in utero are indeed within the range of fetal detection thresholds. Nevertheless, most previous investigations have relied on temporally remote postnatal expressions of prenatal sensory experiences and, therefore, do not provide direct access to fetal sensory function or experiential events as they exist in utero.

There is extensive evidence for fetal sensory function when strong nonbiological stimuli are applied (e.g., 
Bradley \& Mistretta, 1975; Gottlieb, 1971; Narayanan, Fox, \& Hamburger, 1971; Oppenheim, 1972; Ronca \& Alberts, 1990; Smotherman \& Robinson, 1988; Smotherman, Robinson, Ronca, Alberts, \& Hepper, 1991). Suprathreshold sensory testing of the prehatching and prenatal specimen has been important in illuminating sheer capacity present during early development. Less well addressed are questions of fetal responsivity to less intense stimuli that naturally and regularly occur within the prenatal habitat. Naturally occurring prenatal events comprise an important set of potential stimuli for experience-mediated epigenetic mechanisms of development (Hall \& Oppenheim, 1987; Kuo, 1967). In this regard, it is fundamentally important to understand both the prenatal environmental stimuli and the sensoryperceptual capacities of the inhabitants of prenatal environments. Gottlieb's extensive studies of species recognition of maternal calls in ducklings (e.g., Gottlieb, 1987,1988 ) demonstrate the embryo's exquisite sensitivity to fine details of prenatal stimuli-in this case, to specific frequencies and temporal patterns of acoustic stimulation.

Unfortunately, few studies have examined the effects of naturally occurring biological stimuli on the behavior of mammalian perinates. One reason for the paucity of experimental studies may be that such investigations require detailed information about the intrauterine and natal habitats, and only a few such descriptions are available (Fifer \& Moon, 1988; Gerhardt, Abrams, \& Oliver, 1990; Ronca et al., 1993; Vince, Armitage, Baldwin, Toner, \& Moore, 1982; Vince, Billing, et al., 1985; Vince, Lynch, Mottershead, Green, \& Elwin, 1985). Empirical descriptions of the prenatal environment are further complicated by potentially buffering effects of the fetus's fluid-filled amniotic sac that may limit or reduce the intensity of extrinsic stimulation (Bradley \& Mistretta, 1975; Reynolds, 1962; Ronca \& Alberts, in press). Most previous analyses have focused on the intrauterine acoustic environment (Fifer \& Moon, 1988; Gerhardt et al., 1990; Vince, Armitage, Baldwin, et al., 1982; Vince, Billing, et al., 1985), although we have described tactile, vestibular, and thermal stimuli that normally impinge upon the fetal and newborn Norway rat (Ronca et al., 1993).

Our analysis revealed that by-products of maternal behavior and physiology barrage the fetuses with specific and patterned stimuli during gestation and parturition. The dam's forward locomotion exposes fetuses to linear acceleration. During rearing, the dam raises her forebody to vertical, producing angular acceleration of fetuses. The dam's self-grooming produces various forms of stimulation: During abdominal grooming, she exerts pressure on the underlying fetuses in utero. During hindlimb scratching, the dam rapidly vibrates the fetuses. During parturition, labor contractions compress fetuses in utero. The dam licks and handles each pup as it is born, providing vigorous tactile and vestibular stimulation. Newborn pups are also exposed to strong thermal stimulation, cooling rapidly to the temperature of the postnatal environment (Alberts, Ronca, \& Blumberg, 1992).

In the present experiment, we simulated some of the naturally occurring stimuli associated with gestation, labor, and delivery that impinge upon the fetus as it becomes a newborn. Late gestation fetal rats were stimulated, and cardiac and behavioral responses were then measured. The form and magnitude of each stimulus was determined using data from previous studies of parturition in the rat (Alberts \& Ronca, 1993; Dollinger, Holloway, \& Denenberg, 1980; Fuchs, 1969, 1978; Higuchi, Uchide, Honda, \& Negoro, 1987; Ronca et al., 1993; Rosenblatt \& Lehrman, 1963). Our goal was to approximate as closely as possible the parameters of biological stimuli associated with gestation and birth in the rat. The stimuli employed were (1) angular acceleration, to mimic rearing of the pregnant dam, (2) vibration, to mimic hindlimb scratching, (3) compression, to mimic labor contractions, (4) stroking, to mimic postpartum licking by the dam, and (5) cooling, to mimic the thermal characteristics of the postpartum nest. Each stimulus was applied for $5 \mathrm{sec}$ in order to facilitate comparisons between responses to the different stimuli, thus overlooking differences in the durations of the natural events upon which our manipulation was based.

\section{METHOD}

\section{Subjects}

Seventy-three fetuses from 37 rat dams ( 1 or 2 fetuses per dam) were tested in this experiment. The subjects were the offspring of Sprague-Dawley rats (70-80 days) time-bred in the Indiana University colony. Pregnant dams were housed in standard polyurethane maternity tubs in a colony room maintained at $22^{\circ} \mathrm{C}$, under a 16:8-h light:dark cycle. Purina Rat Chow and water were available ad lib. Vaginal cytology was examined each day of the breeding period to identify the date of conception (the first day on which sperm was observed was designated as Gestational Day 0 [GD 0]; day of birth = GD 22). The animals were maintained and used in accordance with standards for care and use prescribed by the NIH and Indiana University.

\section{General Procedure}

The fetuses were tested using established procedures for prenatal observation (Narayanan et al., 1971; Smotherman \& Robinson, 1986). Briefly, a spinal transection eliminated maternal sensation and voluntary movement in the lower body. On GD 21, each dam was anesthetized with methoxyflourane (Metofane, PittmanMoore), then given an intrathecal injection of $100 \%$ ethanol $(100 \mu \mathrm{l})$ between the first and second lumbar vertebrae. The dam was placed in a Plexiglas chair, her lower body immersed in an isotonic buffered saline bath $\left(37.5 \pm 0.5^{\circ} \mathrm{C}\right)$, and her uterus gently externalized into the bath through a midline incision in the lower ventrum. To minimize residual effects of general anesthesia on fetal subjects, the onset of testing was delayed for $20 \mathrm{~min}$ following spinal transection of the dam. A small incision was then made along the antimesometrial border of the uterus overlying the target fetus. The fetus was gently externalized from the uterus, its embryonic membranes removed, then positioned in a test container that was submerged within the heated waterbath (described below). Umbilical connections to the dam were preserved throughout the test. 


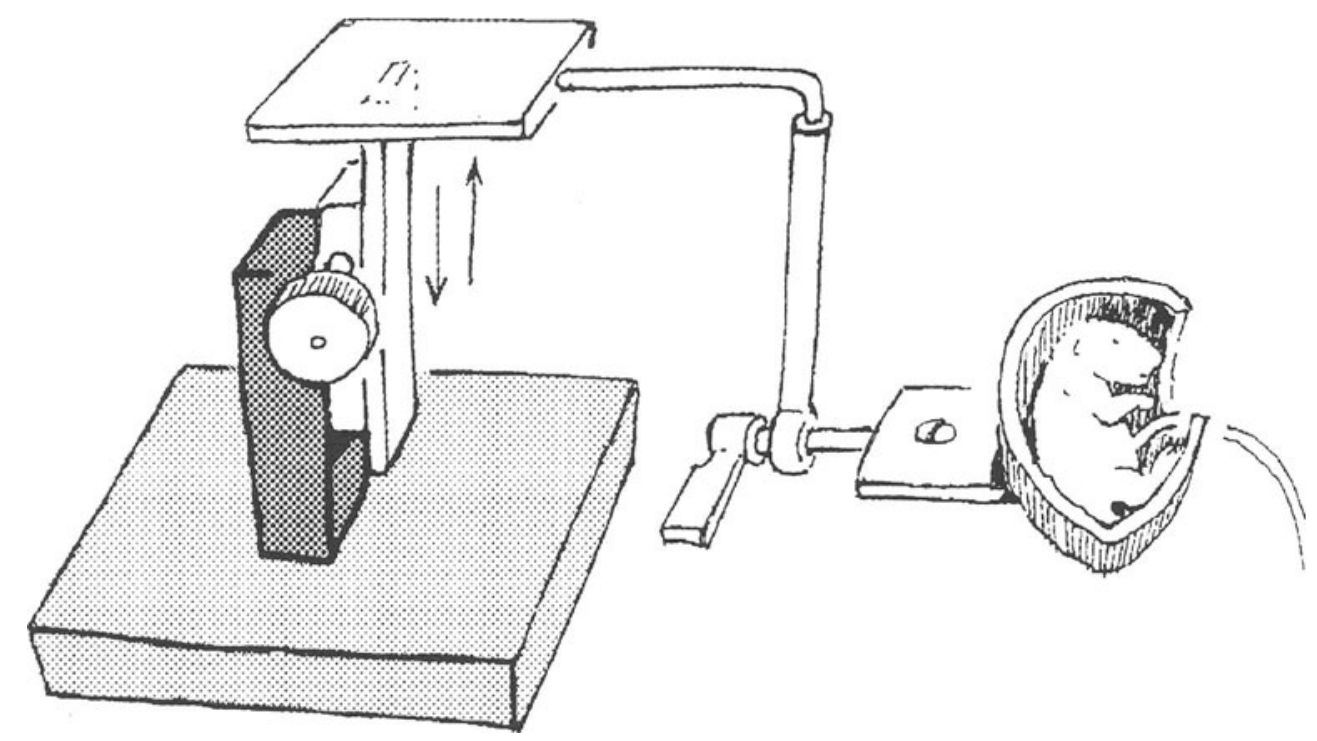

Figure 1. The target fetus was externalized from the uterus and amniotic membranes and placed in an "egg cup" for testing. The cup was attached to a microscope stand, which permitted fine vertical control over the position of the fetus in the waterbath, thereby preventing application of tension to the umbilical cord. This configuration stabilized the fetus, enabling controlled reliable application of stimuli. Note the aperture in the cup permitting uninterrupted passage of the umbilical cord to the placenta.

\section{Test Apparatus}

For testing, the fetus was positioned within a rubber-lined eggshaped cup $(3 \times 5.5 \times 3 \mathrm{~cm})$ attached to a microscope stand (Figure 1). An aperture along one side of the egg cup $(1 \times 0.5 \mathrm{~cm})$ provided a trough within which the umbilical cord rested. This configuration provided fine control over the fetus's position within the waterbath by permitting vertical and horizontal adjustments that maintained the fetus in close proximity to its uterine attachment site.

\section{Stimuli}

Stimuli were designed to approximate tactile, vestibular, and thermal characteristics of the rat's uterine and natal environments. Fetuses were presented with one of five different stimuli: angular acceleration $(n=13)$, vibration $(n=10)$, compression $(n=11)$, stroking $(n=10)$, or cooling $(n=11)$. An additional group was run as a control for the cooling procedure ( $n=12$; see below). Each stimulus was presented for $5 \mathrm{sec}$.

\section{Angular Acceleration of Fetal Rats \\ to Mimic Maternal Rearing}

Selection of stimulus parameters. During late gestation, pregnant rats rear more than 300 times per day (Ronca et al., 1993). The dam's body axis moves through angles ranging from $60^{\circ}$ to $73^{\circ}$ within $1 \mathrm{sec}$. For the present study, we used a stimulus magnitude near the upper end of the range $\left(70^{\circ}\right)$ in order to maximize the likelihood that fetuses would detect stimulation.

Stimulus delivery. Angular acceleration of fetuses was produced by tilting the test apparatus. Figure 2 shows an illustration of the fetus within the test cup at the prestimulus position (lefthand diagram) and during angular acceleration (righthand diagram). The test cup was attached to a small platform that was fitted with a small handle. The handle was affixed to the cup assembly at the juncture between the cup and the microscope stand (see Figure 2). To tilt a fetus, the experimenter manually rotated the handle in a clockwise direction, thereby accelerating the test cup and the fetus within it. During a single trial, each fetus was tilted $70^{\circ}$ from a lateral to head-up position, then returned to the resting position. A "stop" installed on the handle corresponded to the apex of the $70^{\circ}$ tilt and ensured that the magnitude of stimulation was reproducible. Each excursion from $0^{\circ}$ to $70^{\circ}$ to $0^{\circ}$ was produced at a constant rate over the 5 -sec period (i.e., $28 \% \mathrm{sec}$ ).

\section{Vibration of Fetal Rats to Mimic Maternal Hindlimb Scratching}

Selection of stimulus parameters. During hindlimb scratching, the dam applies to her abdomen rapid movements of one hindpaw, thereby vibrating fetuses in utero (Ronca et al., 1993). Frame-
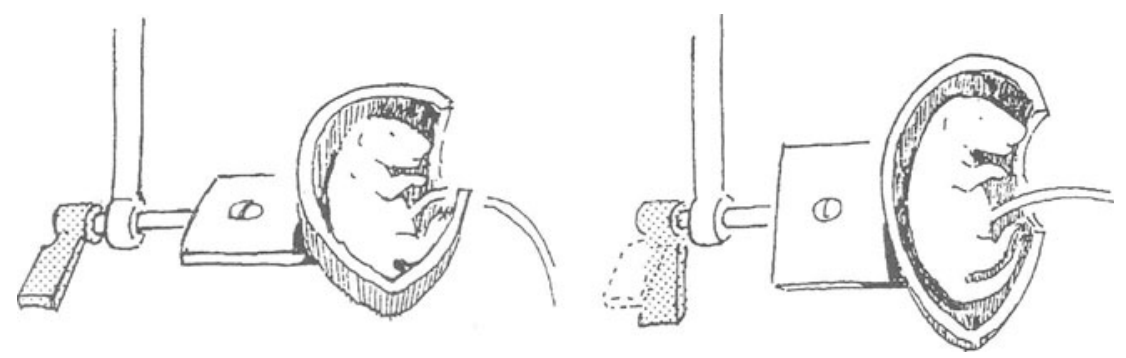

Figure 2. Angular acceleration, to mimic rearing of the pregnant dam, was produced by tilting the cup $70^{\circ}$ from a lateral to head-up position. 
by-frame analysis of videotaped hindlimb scratching by several late pregnant dams revealed that the dam's hindpaw contacts her abdomen approximately every $200 \mathrm{msec}$ or five times per second. Fetuses in utero would therefore be exposed to vibration at a frequency of about $5 \mathrm{~Hz}$.

Stimulus delivery. Vibration associated with maternal hindlimb scratching was produced using a small cylindrical vibrator $(5 \times 2 \mathrm{~cm})$ attached to the base of the egg cup (Figure 3 ). The vibrator consisted of a DC motor with a concentric weight attached at one end. The entire assembly was placed in a polyurethane cylinder, which was coated with molded latex. The vibrator was attached to the bottom of the capsule and, when activated, vibrated the test cup containing the subject. This configuration permitted the application of controlled reproducible vibrations (displacement of the cup was approximately $0.5 \mathrm{~mm}$ at $5 \mathrm{~Hz}$; rise time $<100 \mathrm{msec}$ ) to fetuses. A single stimulus consisted of a continuous, 5 -sec period of vibration. Stimulus presentation and timing were controlled by solid-state programming apparatus interfaced to a microcomputer system.

\section{Compression of Fetal Rats to Mimic Uterine Contractions}

Selection of stimulus parameters. During labor, the rat fetus is exposed to physical compression associated with uterine contractions (Ronca et al., 1993). The amount of force exerted on the rat fetus during uterine contractions has been measured directly in studies of intrauterine pressure (IUP) change during labor. In these studies, a single conceptus (i.e., a fetus within its embryonic membranes) is removed from the dam's uterus and replaced with a saline-filled balloon connected to a pressure transducer. Using this technique, IUP changes during labor and parturition are reported at levels ranging from 5 to $25 \mathrm{mmHg}$ (Alberts \& Ronca, 1993; Fuchs, 1969; Higuchi et al., 1987), the magnitude of uterine contractions generally increasing from the first through the third stage of labor (Fuchs, 1969, 1978; Higuchi et al., 1987). For the present study, we selected a stimulus magnitude of $15 \mathrm{mmHg}$, since most fetuses are likely to be exposed to contractions nearing or exceeding this level during labor contractions.

Stimulus delivery. Five seconds of continuous pressure was delivered to each subject fetus by compressing it under an inflated latex balloon. To apply reliably a controlled pressure to each subject, the balloon was attached to a commercial gram scale (Figure 4). The balloon was inflated to approximately $3 \mathrm{~cm}$ in diameter, which filled the test capsule during compression of the fetus. Using this procedure, the scale registered a gram equivalent to 15 $\mathrm{mmHg}$ pressure, as determined by a calibration procedure conducted prior to each trial. For each stimulus presentation, the

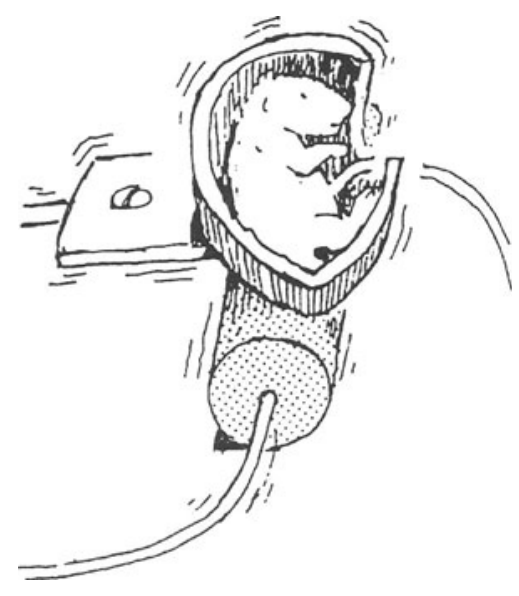

Figure 3. Vibration, to mimic hindlimb scratching of the dam, was produced by applying a small vibrating motor to the base of the cup.

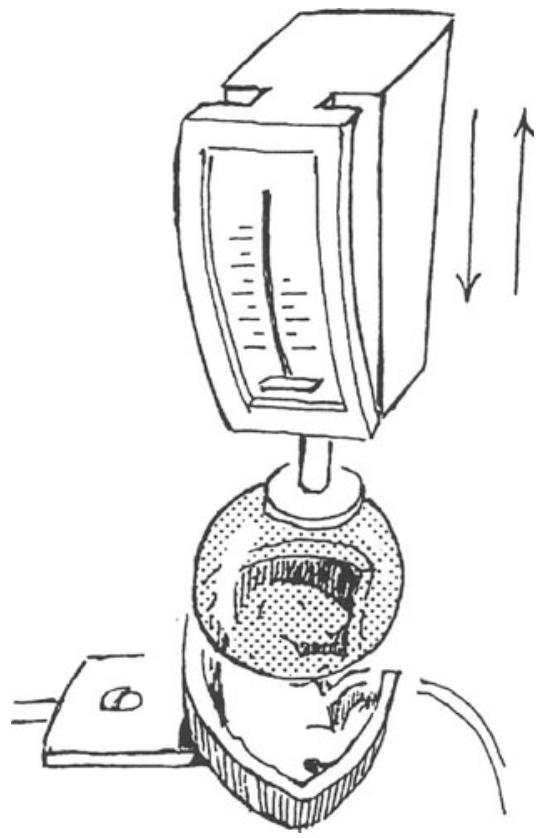

Figure 4. Compression, to mimic labor contractions, was produced by applying an inflated latex balloon attached to a commercial gram scale (pressure $=15 \mathrm{mmHg}$ ) across the fetus's body surface.

balloon-scale assembly was inverted and manually compressed along the full length of the fetus for a continuous 5 -sec duration.

Prior to each run, an artificial calibration fetus (consisting of a water-filled balloon connected to a pressure transducer) was compressed with the balloon-scale assembly and the output measured on a polygraph (Grass Model 7). By constructing the calibration fetus to match as closely as possible the size, volume and turgor of an actual fetus, we were able to estimate the gram equivalent of $15 \mathrm{mmHg}$ pressure on the balloon assembly.

\section{Stroking of Fetal Rats to Mimic Postpartum Licking}

Selection of stimulus parameters. When the newborn rat emerges from the birth canal, the rat dam engages in extensive licking and handling of the pup to remove its birth membranes. Using frame-by-frame analysis of videotaped birth sequences, we found that rat dams lick their newborn offspring at a rate of about five times per second (Ronca \& Alberts, 1993).

Stimulus delivery. To simulate the dam's postpartum licking of pups, we constructed an array of pliable "tongues" $(0.6 \times 0.04 \mathrm{~cm})$ custom-formed from liquid latex. Five tongues were attached to a set of flexible plastic spokes ( $2 \mathrm{~cm}$ long, $1 \mathrm{~mm}$ diameter) that radiated from the axis of a small motor $(5 \mathrm{~Hz}$; Figure 5). For stimulus presentation, the assembly was positioned for contact of the tongues with the fetus's upper body, and the motor was activated for $5 \mathrm{sec}$. Stimulus presentation and timing were controlled by solid-state programming apparatus interfaced to a microcomputer system.

\section{Cooling of Fetal Rats to Mimic Delivery Into the Nest}

Selection of stimulus parameters. In our laboratory, air temperature within the nest during parturition and throughout the first postpartum hour was approximately $25^{\circ} \mathrm{C}$.

Stimulus delivery. In the present study, the subjects were fetuses with intact umbilical connections to the dam. Accordingly, fetuses were maintained throughout the test in a heated waterbath at normal intrauterine temperature $\left(37.5^{\circ} \mathrm{C}\right)$. To simulate the thermal contrasts of birth, we exposed fetuses to a discrete $(5-\mathrm{sec})$ 


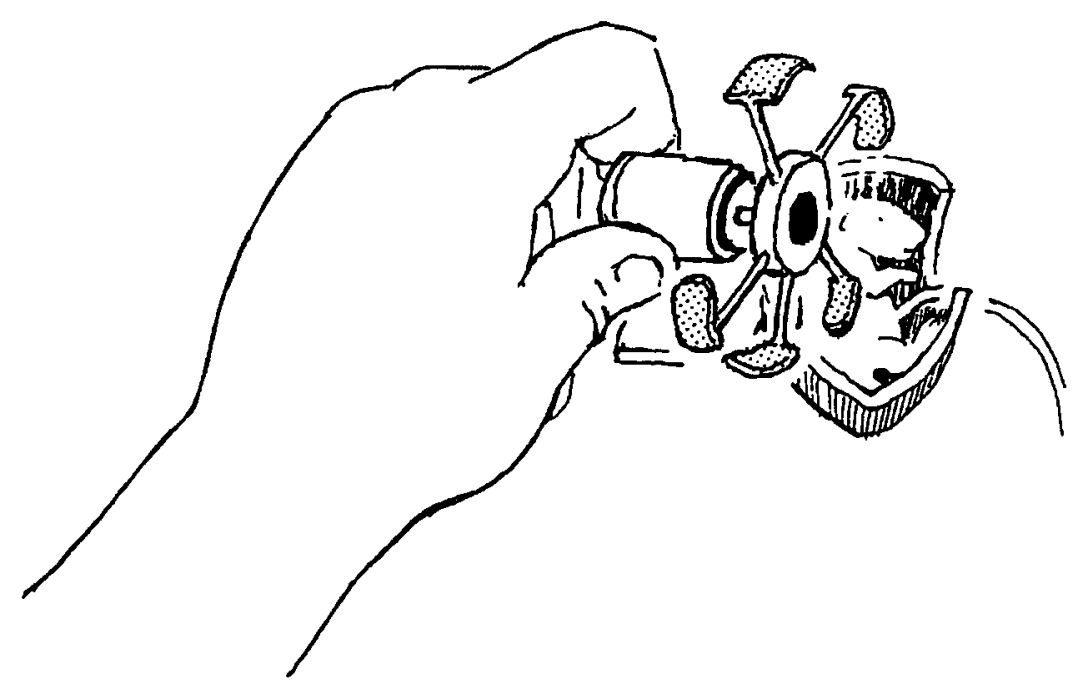

Figure 5. Stroking, to mimic postpartum licking, was produced by applying a set of moving latex "tongues" to the fetus's body surface.

period of cooling by infusing $25^{\circ} \mathrm{C}$ water into the test apparatus (i.e., the egg cup) for $5 \mathrm{sec}$, followed by replacement of heated water $\left(37.5^{\circ} \mathrm{C}\right)$ into the cup. This was accomplished by filling each of two 35-cc syringes with buffered saline solution, and maintaining one at $25^{\circ} \mathrm{C}$, and the other at $37.5^{\circ} \mathrm{C}$. In order to cool fetuses, the tip of the $25^{\circ} \mathrm{C}$ syringe was placed next to the fetus within the egg cup, and its contents were infused into the capsule (Figure 6). Five seconds following stimulus onset, warm saline was similarly infused into the cup. A temperature probe seated at the base of the cup verified the drop in fluid temperature during the 5-sec stimulus presentation. To control for the tactile effects of fluid infusion, a separate group of subjects was exposed to heated water $\left(37.5^{\circ} \mathrm{C}\right)$ in lieu of cooled water $\left(25^{\circ} \mathrm{C}\right.$ ). (In this case, the subjects received two infusions of heated saline separated by a $5-\mathrm{sec}$ interval.)

\section{Test Procedure}

Two subjects were tested from each dam, one from each uterine horn. The uterine wall was incised $(10-15 \mathrm{~mm})$ at the antimesometrial border between the first and second fetus at the ovarian end of the horn. The fetus in the second uterine position was externalized from the uterus and positioned laterally within the egg cup (see Figure 1), adjusted to a height just overlying the uterus, but submersed within the waterbath. The test cup supported the target fetus, afforded protection from tension on the umbilical cord, served as a buffer from movements of the dams and siblings, and permitted application of controlled reproducible stimuli.

At the onset of testing, each fetus was fitted with EKG electrodes. Heart rate (HR) was measured and behavior was videotaped for $30 \mathrm{sec}$. A single stimulus was presented for $5 \mathrm{sec}$, and EKG measures were collected for an additional $55 \mathrm{sec}$.

At the completion of testing, the umbilical attachment of each subject was carefully inspected in order to ensure that the subjects were not subject to hypoxia during the test. If bleeding was observed at the site of placental attachment to the uterus (indicating placental separation), the subject fetus was eliminated from the subject pool prior to data analysis $(n=6)$. At the completion of testing, fetuses were weighed and their gender determined. Dams and fetuses were sacrificed with $\mathrm{CO}_{2}$.

\section{EKG Data Collection}

EKG data collection was accomplished using established techniques for measuring HR of perinatal rats (Ronca \& Alberts,
1990). Two 30-cm lengths of teflon-insulated nickel electrode wire ( $36 \mathrm{ga}$; Formex Evanohm, Pelican Wire Co.), bared $2 \mathrm{~mm}$ at one end, served as electrodes. Prior to testing, one electrode was inserted subcutaneously just below the ventral aspect of the ribcage and the other was inserted in the nape of the neck using a disposable hypodermic needle ( $27 \mathrm{ga}, 3 / 4 \mathrm{in}$.). EKG signals were amplified online by a Grass Model 79D polygraph and recorded (chart speed $=25 \mathrm{~mm} / \mathrm{sec}$ ) in order to preserve a permanent written record of each trial. The EKG signal was simultaneously coupled to a tachograph and interfaced to an IBM 386 computer. Data storage and analysis were accomplished using Berntson's (1990) Heart V6.0 software. Heart period (HP, or interbeat intervals [IBIs]) was measured in milliseconds. Stimulus presentations were time-locked to the EKG measures and controlled by the microcomputer. For each trial, baseline EKG was collected for $30 \mathrm{sec}$. At that time, the microcomputer system activated solid-state programming apparatus and initiated a low-amplitude tone. A single stimulus was delivered on each trial. Vibration and stroking stimuli were controlled directly by the computer, whereas angular acceleration, compression, and thermal stimuli were delivered manually upon sounding of the acoustic signal. EKG measures were collected for $60 \mathrm{sec}$ following stimulus onset.

\section{Data Analysis}

To identify movement artifacts, the Heart V6.0 editing program was used to locate IBIs that deviated more than $15 \%$ from surrounding values. These outlier IBIs were checked by direct inspection of the polygraph record, and the correct value was substituted if an error had occurred. (Errors were clearly detectable on the permanent record: The form of the EKG signal was rarely obscured even when a computer error occurred.) For purposes of analysis, HP was apportioned into 1-sec bins for each trial, then converted to HR (beats per minute [BPM]). For analysis of baseline HR, between group comparisons were made across the six 5 -sec (prestimulus) bins of averaged HR. For analysis of HR responses, a matched pairs $t$ test and a repeated measures analysis of variance (ANOVA) was conducted for each stimulus. For matched-pairs $t$ tests, HR values were averaged across $20 \mathrm{sec}$ immediately preceding stimulation and were compared with the average HR during the $20 \mathrm{sec}$ following stimulus onset. For the ANOVA, difference scores were calculated by subtracting each of 125 -sec poststimulus bins of averaged HR from the 5-sec bin immediately preceding stimulus onset. 


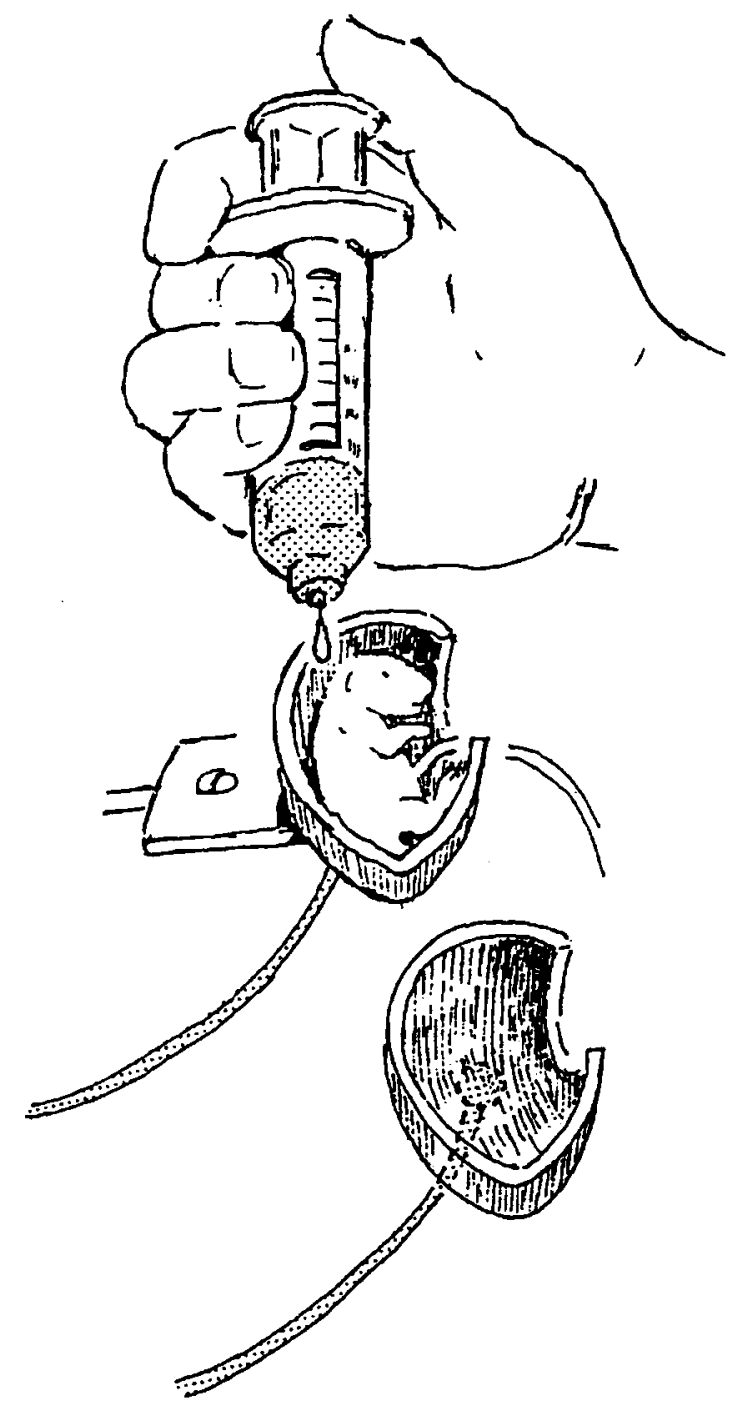

Figure 6. Cooling, to mimic the thermal effects of birth, was produced by infusing $25^{\circ}$ buffered saline solution into the test cup. The thermistor positioned at the base of the cup was connected to a digital thermometer and permitted direct monitoring of water temperature below the pup.

\section{Behavioral Measures}

Videorecords were made as described previously (Ronca, Kamm, Thelen, \& Alberts, 1994). Briefly, a color video camera (Sony DXC-107) fitted with a high-resolution lens (SchneiderKreuznach Cinegon 1:1.8/10) and connected to a VCR (tape speed $=60 \mathrm{frames} / \mathrm{min}$ ) was positioned vertically over the waterbath at a focal length of $8 \mathrm{~cm}$. Each subject was videotaped for the entirety of a 90 -sec trial.

Motor activity of fetal rats was coded from videotape by trained observers. Videotapes were analyzed frame by frame using a VCR with full shuttle/jog control over tape speed in both forward and reverse directions (Sony AG1960). Videotapes were reviewed at normal speed and in slow motion in order to identify the onset and offset of each response to the nearest $0.01 \mathrm{sec}$. This technique provides temporal resolution accuracy within two frames $(0.06 \mathrm{sec})$. A single movement bout was defined as an interval during which any body segment was in motion bounded by a minimum of two consecutive frames during which no movement occurred. Per- centage of movement was calculated for $30 \mathrm{sec}$ prestimulus and for $30 \mathrm{sec}$ poststimulus for each group.

\section{RESULTS}

\section{Baseline HR and Behavioral Activity}

Baseline measures of HR and activity were identical across groups. Table 1 presents HR and percent activity averaged over the $30-\mathrm{sec}$ prestimulus period for each subject group. A one-way ANOVA conducted on each measure revealed no group differences in baseline HR $[F(5,66)=0.35$, n.s. $]$ or percent activity $[F(5,60)=$ 0.47 , n.s.]. Resting HR levels closely matched those previously reported for fetal rats (Preuss \& Weitman, 1987; Smotherman et al., 1991).

\section{Cardiac Responses to Stimuli Associated With Gestation and Parturition}

Figure 7 summarizes the fetal rats' average HR responses to angular acceleration, vibration, compression, stroking, and cooling. Response form was predominantly bradycardiac: $97 \%$ of the 54 subjects tested in these conditions responded with HR deceleration. Heart rate responses were robust. The smallest average group response (calculated over $60 \mathrm{sec}$ following stimulus onset) was $-11.19( \pm 21.3) \mathrm{BPM}$ in fetuses exposed to simulated postpartum licking (Figure 7, righthand column, center); the largest group response was -41.18 $( \pm 24.76)$ BPM, displayed by cooled fetuses (Figure 7 , lefthand column, bottom). For each condition, fetal HR responses began within $5 \mathrm{sec}$ of stimulus onset and persisted $20 \mathrm{sec}$ or more into the poststimulus measurement interval. Peak responses occurred within $20 \mathrm{sec}$ of stimulation, except in the cooled group, which showed an initial deceleration at about $10 \mathrm{sec}$ poststimulation and a second, larger, deceleration $15 \mathrm{sec}$ later. In contrast, fetuses in the thermal control condition (Figure 7, righthand column, bottom) did not respond to the presentation of heated water. Matched pairs $t$ tests were conducted on each stimulus condition to compare average $\mathrm{HR}$ values during the 20 -sec prestimulus measurement interval and the first $20 \mathrm{sec}$ following stimulus onset. These analyses indicated that for each form of stimulation, stimulus-evoked change from baseline was significant [angular acceleration, $t(11)=2.2, p<.05$;

Table 1

Average Baseline Heart Rate (Mean $\pm S E M$ ) and Movement Activity (Mean $\pm S E M$ ) of Day 21 Fetal Rats in Different Stimulus Conditions During a 30-Sec Measurement Interval

\begin{tabular}{lcccrrrr}
\hline & \multicolumn{3}{c}{ Heart Rate (BPM) } & & \multicolumn{3}{c}{ Activity (\%) } \\
\cline { 2 - 4 } \cline { 7 - 8 } Stimulus Condition & $n$ & $M$ & $S E M$ & & $n$ & $M$ & $S E M$ \\
\hline Angular acceleration & 12 & 299.0 & 68.3 & & 11 & 13 & 4 \\
Vibration & 10 & 277.8 & 74.7 & & 10 & 10 & 4 \\
Compression & 11 & 292.4 & 64.8 & 10 & 15 & 3 \\
Rapid strokes & 10 & 274.4 & 59.5 & 9 & 9 & 4 \\
Cooling & 11 & 298.9 & 67.5 & & 10 & 8 & 3 \\
Thermal control & 12 & 304.8 & 74.0 & 11 & 14 & 5 \\
\hline
\end{tabular}


$70^{\circ}$ Angular Acceleration

(Rearing)
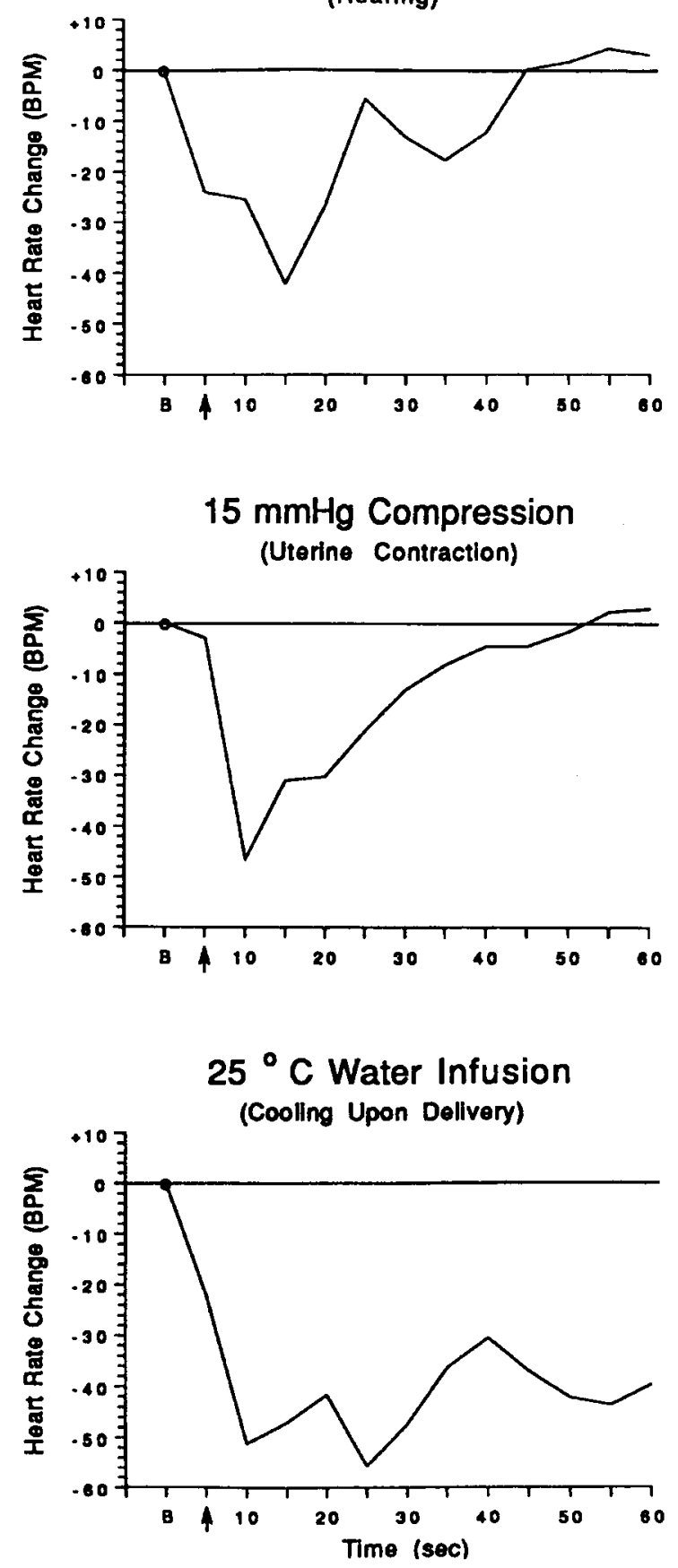
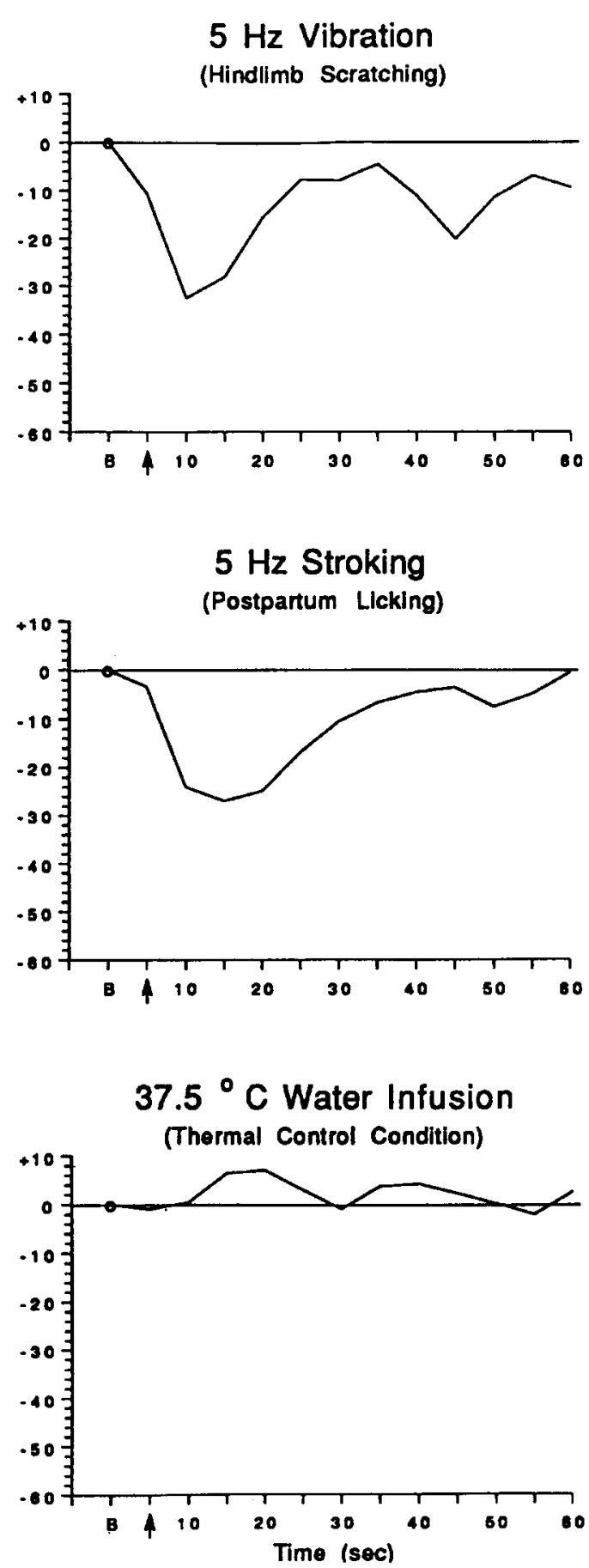

Figure 7. Average cardiac response of Day 21 fetal rats in the angular acceleration (top left), vibration (top right), compression (middle left), stroke (middle right), cool (bottom left), and thermal control (bottom right) groups. Cardiac responses are plotted as deviation from prestimulus baseline (B) in 5-sec bins for 60 sec following stimulus onset.

vibration, $t(9)=2.5, p=.05$; compression, $t(10)=3.0$, $p<.01$; stroking, $t(9)=3.0, p<.05$; cooling, $t(10)=$ $4.9, p<.01]$, except for the thermal control condition $[t(11)=0.43$, n.s. $]$.

A repeated measures ANOVA (stimulus group $\times$ time bin) was used to compare average $H R$ across stimulus groups (excluding the thermal control condition). Data were analyzed across consecutive 5-sec time bins consisting of 1 prestimulus and 12 poststimulus bins. Twelve difference scores were calculated by subtracting each poststimulus bin from the prestimulus bin. (The prestimulus bin was set to zero; this data point was included 
in the analysis.) This analysis revealed a significant main effect of stimulus group $[F(4,49)=2.9, p<.05]$ and a significant main effect of time bin $[F(12,588)=612.5, p$ $<.01]$, with no interaction between factors $[F(48,588)=$ 1.14 , n.s.). Post hoc pairwise comparisons using a Fisher PLSD test $(p<.05)$ revealed that fetuses in the cool condition responded with significantly greater HR deceleration than did fetuses in all of the other stimulus conditions. Subjects in the cool condition showed the largest and most protracted HR response, remaining bradycardiac throughout the poststimulus interval. No other differences emerged from these comparisons.

Post hoc analysis of time bin (Fisher PLSD test, $p<$ .05 ) revealed that prestimulus baseline (Figure 7, "B") differed significantly from all but the last poststimulus bin $(60 \mathrm{sec})$. The following differences also emerged from this analysis: Average HR at $5 \mathrm{sec}$ differed from that at 10,15 , and $20 \mathrm{sec}$, at $10 \mathrm{sec}$ differed from that at each point between 25 and $60 \mathrm{sec}$, at $15 \mathrm{sec}$ differed from that at each point between 25 and $60 \mathrm{sec}$, at $20 \mathrm{sec}$ differed from that at each point between 35 and $60 \mathrm{sec}$, at $25 \mathrm{sec}$ differed from that at 55 and $60 \mathrm{sec}$, and at $30 \mathrm{sec}$ differed from that at $60 \mathrm{sec}$.

A separate ANOVA (thermal condition $\times$ bin) comparing subjects in the cooled group with those in the thermal control group revealed a significant main effect of group $[F(1,21)=32.15, p<.01]$, but no effect of bin $[F(11,231)=1.26$, n.s. $]$ or interaction between factors $[F(11,231)=1.46$, n.s. $]$.

Examination of individual responses also revealed individual differences in magnitude of HR change. Individual $\mathrm{HR}$ responses ranged from +69.3 to $-89.3 \mathrm{BPM}$, with extreme responses contributed by members of the angular acceleration and vibration groups, respectively.

\section{Behavioral Responses to Stimuli Associated With Gestation and Parturition}

Behavioral responses to stimulation generally consisted of behavioral activation and included movements of the head, forelimbs, hindlimbs, and trunk. Behavioral reactions were closely coupled to stimulation period (i.e., occurred either during or immediately following stimulation) and subsided within $30 \mathrm{sec}$. Figure 8 shows percentage of time spent moving during the $30-\mathrm{sec}$ prestimulus measurement interval, relative to the $30-\mathrm{sec}$ period following the onset of stimulation, for each group. Stimulus-evoked activity was significant for each subject group [matched-pairs $t$ tests: angular acceleration, $t(10)=-2.35, p<.05$; vibration, $t(8)=-3.28$, $p=.05$; compression, $t(9)=-4.36, p=.01$; stroking, $t(8)=3.0, p<.05$; cooling, $t(9)=-3.83, p<.05]$, except for the thermal control condition $[t(10)=-0.55$, n.s.].

A one-way ANOVA comparing the five stimulus groups (stimulus group $\times 5$-sec bins) revealed significant differences in the percent of time spent moving in the different stimulus groups $[F(4,49)=3.25, p<.05]$.

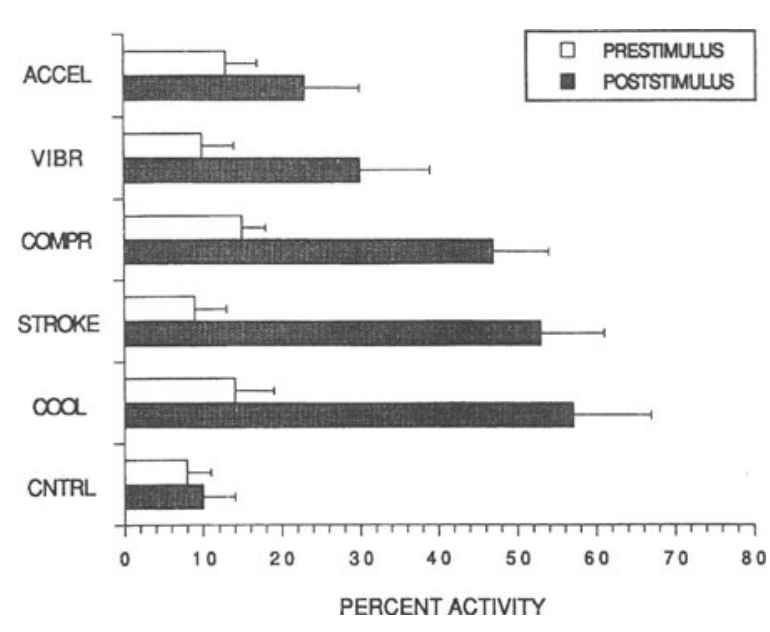

Figure 8. Average behavioral response of Day 21 fetal rats in the angular acceleration, vibration, compression, stroke, cool, and thermal control groups. Responses are plotted as percent change from baseline in overall time spent moving for $30 \mathrm{sec}$ before and $30 \mathrm{sec}$ following stimulus onset.

Angular acceleration and vibration evoked significantly less behavioral activity than did stroking and cooling (Fisher PLSD, $p<.05$ ). A separate ANOVA comparing cooling and thermal control conditions revealed significantly more behavioral activity following cooling compared with that found for the thermal control tests $[F(1,29)=12.35, p<.05]$.

\section{Relationship Between Cardiac and Behavioral Responses to Stimulation}

Fetuses responded to angular acceleration, vibration, mechanical compression, stroking, and cooling with both bradycardia and motor activation. To characterize the strength of relationship between cardiac and behavioral responses, we calculated the percent change from baseline for each response measure for the $30 \mathrm{sec}$ preceding and the $30 \mathrm{sec}$ following stimulus onset. Data from each stimulus group (but not the thermal control group) were submitted to correlational analysis, which revealed that cardiac and behavioral response magnitudes were unrelated to one another $\left(R^{2}=.069\right.$, n.s. $)$.

\section{DISCUSSION}

Fetal rats responded to angular acceleration, vibration, compression, stroking, and cooling with changes in heart rate and behavior. Each stimulus was calibrated to approximate naturally occurring levels of intrauterine stimulation associated with specific activities of the rat dam. Stimuli were designed to mimic the intrauterine concommitants of maternal rearing, hindlimb scratching, labor contractions, and the postnatal events of licking by the dam, as well as exposure to nest temperature. The results of this investigation strongly suggest that 
during late gestation, particular features of the pregnant mother's activities are sensed by the fetus. The present data similarly suggest that the Day 21 rat fetus's sensoryperceptual apparatus can transduce into experience the kinds and levels of stimulation that exist in utero, during labor, and immediately postpartum.

\section{Cardiac Responses to Stimuli Associated With Gestation and Parturition}

Fetal rats responded to each stimulus type with phasic HR responses following the same general pattern: Stimulation produced an immediate significant drop in HR (averaging about $13 \mathrm{BPM}$ ), followed by further deceleration at 10-15 sec poststimulus (maximal deceleration averaged about 35 BPM below baseline). At $20 \mathrm{sec}$, the response trajectory began a progressive return to prestimulus values, leveling off at $60 \mathrm{sec}$ poststimulus. Prestimulus HR did not differ from HR at $60 \mathrm{sec}$ poststimulus.

It is striking that fetal rats' responses to biological levels of stimulation are similar to those obtained previously for nonbiological stimuli: We reported nearly identical HR decelerations to intraoral infusions of lemon extract (Ronca \& Alberts, 1990; Smotherman et al., 1991). The lack of differences in response form, latency, and duration may reflect stimulus characteristics. In this study, we did not systematically vary stimulus intensity, rise time, or duration. Thus, we cannot specify the relationship between a given stimulus and response at this time. In other words, it is not clear whether the observed HR decelerations represent a singular immutable response pattern that is characteristic of fetal rats or whether response form is shaped by stimulus characteristics in these subjects. In this regard, cardiac response patterns of fetal rats merit further study since fetuses are normally exposed in utero to a variety of stimulus forms, and the extent to which fetal behavior is shaped to different stimuli may provide a window into the ontogeny of sensory and behavioral integration during prenatal life.

The only difference in HR responses that emerged in this study was that fetuses in the cooled group displayed significantly greater HR change than did those in other stimulus conditions. There are several possible explanations for the cooled fetuses' accentuated response magnitudes. First, cooling (which mimics the thermal effects of birth) may be a relatively intense sensory stimulus, thereby evoking a larger cardiac response. Second, fetuses are accustomed to a warm intrauterine environment characterized by minimal thermal fluctuation (Dawes, 1968). The sharp drop in ambient temperature associated with birth is likely to comprise the pup's first experience with intense thermal stimulation in general, and with cool temperatures in particular. In this regard, the exaggerated cardiac deceleration may involve a response to novelty. We suspect that rat fetuses have had prior (in utero) experience with cutaneous and vestibular stimuli, but not prior experience with cooling; we might expect the more novel cooling stimulus to elicit a larger orienting reflex (OR). Alternatively, cooling may constitute an aversive sensory stimulus relative to cutaneous and vestibular stimuli. At this time, it is not possible to select among these interpretations. The possibility that these HR decelerations are expressions of fetal ORs is discussed in further detail below.

Subjects in the thermal control condition did not respond to application of heated water, indicating that subjects in the cool condition responded to thermal stimulation rather than water movement. In view of this finding, it is unlikely that water displacement associated with mechanical movements of the various stimulus-delivery devices contributed significantly to the production of sensory-evoked HR and motor responses.

There is some evidence for somatosensory, vestibular, and thermal function in the perinatal rat (Alberts, 1984; Bradley \& Mistretta, 1975; Gottlieb, 1971; Lane, 1917; Narayanan et al., 1971); thus, it is likely that the stimuli employed in this study were detected and processed by fetal afferent systems. Nonetheless, it is important to note that there exist alternate nonsensory explanations for HR responses via effects on other physiological systems. For example, angular acceleration can produce HR change associated with orthostatic hypotension, although the responses observed are typically tachycardiac, rather than bradycardiac (Mountcastle, 1974). Also, direct compression of the heart, rather than compression of the skin, may have been the effective stimulus for HR change to simulated contractions. Finally, the Norway rat fetus is small, unfurred, and thermally fragile. Bradycardiac responses to cooling may have occurred secondarily to core cooling, rather than in response to afferent input. We favor the interpretation that the observed cardiac responses are sensory-evoked. Strong evidence for this position comes from the cooccurrence of HR and motor responses: Behavioral activation would not be expected to occur as an epiphenomenon of orthostatic hypotension, myocardial compression, or core cooling.

\section{Behavioral Responses to Stimuli Associated With Gestation and Parturition}

Spontaneous fetal rat behavior was characterized by rhythmic motility composed of head, forelimb, hindlimb, and trunk movements. This is consistent with previous reports of embryonic behavior in rats and other species (Corner, 1977; Gottlieb, 1968; Oppenheim, 1972; Ronca et al., 1994; Smotherman \& Robinson, 1986). The subjects responded to each form of stimulation with an increase in overall behavioral activity. There were no differences between stimulus conditions in the percentage of elicited movement. Consistent with the results obtained for HR, subjects in the thermal control condition did not respond to water movement with increased activity. Behavioral activation appears to be a general response of fetal rats to sensory input: Previous studies report increased activation of fetal rats to intraoral infusions of nonbiological chemosensants, such as 
lemon and peppermint (Smotherman \& Robinson, 1987, 1988).

\section{Heart Rate Responses of Prenatal Rats as Expressions of the Orienting Reflex}

Over the last few decades, heart rate responses have played an increasingly important role in studies of attention and information processing (see Campbell, Hayne, \& Richardson, 1992, for a recent survey of work in this area). There is a traditional and well-established distinction between orienting and defensive reflexes (Pavlov, 1928; Sokolov, 1963). This distinction is based on differential forms of cardiac response to aversive and nonaversive stimuli: Novel mild stimuli tend to elicit an OR, typically characterized by cardiac deceleration, whereas intense or injurious stimuli elicit cardiac acceleration (Graham, 1992; Sokolov, 1963). The most commonly reported developmental trend in cardiac correlates of the OR is a shift from tachycardia to bradycardia with increasing age (humans: Graham \& Jackson, 1970; rats: Haroutunian \& Campbell, 1981, 1982). In human infants, cardiac acceleratory responses are observed during the first few weeks of life, even to stimuli that typically evoke deceleratory ORs in older infants (Graham \& Jackson, 1970). It is not known whether this shift is due to maturation of autonomic control of the heart or to changes in sensory-perceptual processing associated with functional maturation of afferent systems. Nonetheless, cardiac deceleratory ORs to stimulation have been reported in infants and (more recently) fetuses (humans: K. M. Berg \& Smith, 1983; W. K. Berg \& K. M. Berg, 1979; Berntson, Tuber, Ronca, \& Bachman, 1983; Graham, Anthony, \& Zeigler, 1983; Lecanuet, Granier-Deferre, Cohen, Le Houezec, \& Busnel, 1986; rats: Haroutunian \& Campbell, 1981, 1982; Hayne, Richardson, \& Campbell, 1991, 1992; Ronca \& Alberts, 1990; Ronca, Berntson, \& Tuber, 1985; Smotherman et al., 1991).

\section{Cardiac Control Mechanisms in Perinatal Rats}

The rat heart begins to beat by the 10th conceptional day (Goss, 1938) and is innervated soon thereafter. Sympathetic influences on the heart appear within the first few postnatal days (Kirby \& McCarty, 1987; Seidler \& Slotkin, 1979; Tucker, 1985; Wekstein, 1965), whereas parasympathetic controls do not emerge until the third postnatal week (Adolph, 1967, 1971; Hofer \& Reiser, 1969; Larson \& Porges, 1982; Mills, 1975). In view of the lack of functional tonic control of the perinatal rat heart, it is surprising that HR is labile and responsive to sensory stimulation in these subjects. Yet, there are numerous examples in the literature of deceleratory HR responses to sensory stimuli in both fetal and neonatal rat pups (Haroutunian \& Campbell, 1982; Hayne et al., 1991, 1992; Martin \& Alberts, 1982; Ronca \& Alberts, 1990; Ronca et al., 1985; Smotherman et al., 1991). Sensory-evoked bradycardia can be produced by a withdrawal of tonic sympathetic input to the heart, an in- crease in parasympathetic restraint, or both (Berntson, Boysen, \& Cacioppo, 1992). Given the lack of neural control of the perinatal rat heart, it is interesting that bradycardia is frequently reported in these subjects. One explanation for this apparent discrepancy is that the mechanism underlying phasic bradycardiac responses in rats is increased vagal input to the heart. In support of this interpretation, Haroutunian and Campbell (1981) conducted a pharmacological analysis in preweanling rats, revealing effects of parasympathetic, but not sympathetic, blockade on sensory-evoked responses in 6-day-old rat pups. In addition, bradycardia can be evoked in perinatal rats by direct vagal stimulation (Adolph, 1967; Corey, 1934; Mills, 1975). Although additional work is necessary to verify this interpretation, the existing evidence suggests that central control of the perinatal rat heart may be sufficient to mediate sensoryevoked HR responses.

\section{Sensory-Evoked Responses Within the Natural Habitat of the Uterus}

We have previously suggested that the fetus's habitat (i.e., the uterus) is a dynamic stimulative environment due in large part to the behavioral activities of the pregnant dam and physiological concommitants of pregnancy (Alberts \& Ronca, 1993; Ronca \& Alberts, in press; Ronca et al., 1993). The dam's activities, even those not directed at the offspring, stimulate them. It was therefore important in this study to mimic as closely as possible the forms of stimulation normally present within the uterine and natal habitats.

The precise forms of stimulation used in this study were derived from our analysis of the rat dam's behavior during gestation, labor, and delivery (Ronca et al., 1993). That investigation revealed that over a single $24-h$ period, fetuses in utero may be exposed to over 300 angular accelerations associated with maternal rearing, 125 episodes of vibration produced by the dam's hindlimb scratching, over 100 episodes of compression during labor contractions, over $3 \mathrm{~min}$ of strokes associated with postpartum licking, and, upon delivery into the nest, a drop in temperature exceeding $12^{\circ} \mathrm{C}$. The amount of stimulation presented to fetuses in this study is only a fraction of the amount normally available in utero and during birth. In the present study, we made no attempt to mimic the temporal aspects of stimulation. Instead, each stimulus was presented for an identical continuous $5-\mathrm{sec}$ period, thus enhancing the comparability of fetuses' reactions to the different stimuli. For a subset of stimuli, the 5-sec duration was differed notably from natural values. For example, the typical duration of uterine contractions in the rat exceeds $20 \mathrm{sec}$ (Fuchs, 1969; Higuchi et al., 1987). Newborns are exposed to postpartum cooling for $1 \mathrm{~h}$ or more (Alberts et al., 1992). In contrast, bouts of hindlimb scratching and postpartum licking typically occur within a 5-sec window, and during angular acceleration, dams retain an upright posture for $1-18 \mathrm{sec}$ (Ronca et al., 1993). 
It is impressive that fetuses were able to detect a single episode of stimulation and that stimuli were equally effective in eliciting reactions. Under natural conditions, maternally derived afferent input changes and recurs over time as the dam locomotes, grooms, rears, eats, and drinks. We predict that perinates' responses become modified with repetitive stimulation, as processes of habituation and sensitization emerge and are expressed during development. Further studies are required to specify the temporal pattern of naturally occurring, maternally derived stimulation before effects on perinatal behavior can be studied. It is important to note, however, that concommitant changes in sensory acuity and in the intrauterine environment during the late fetal period in the rat need also be considered in studies of sensoryperceptual processes (Alberts \& Ronca, 1993; Ronca \& Alberts, in press).

One caveat regarding interpretations of the present study is that fetuses were stimulated following removal of the amniotic sac. Oppenheim (1972) reported that chick embryos presented in ovo with tactile and proprioceptive stimulation (produced by inserting a glass probe through the chorioallantoic membrane) did not respond with altered frequency or duration of movement, raising the possibility that physical stimulation within the natural habitat does not instigate behavior in embryos. The possibility exists that fetuses in our study responded to stimulation because they were sensitized by externalization from the sac, but would not necessarily respond in utero. This possibility remains to be tested: There is clearly a need for further examination of fetal sensory and behavioral function within the intrauterine context. In either case, our results demonstrate that fetal rats can detect and respond to the classes and levels of sensory input that are available during gestation and birth.

\section{Cardiosomatic Coupling in Perinatal Rats}

Cardiosomatic coupling is a phenomenon in which deceleratory cardiac responses occur as a direct result of cessation of motor activity, rather than as a centrally mediated component of attention (Obrist, 1981). In the present study, cardiac and behavioral response magnitudes were not related to one another, suggesting that cardiosomatic coupling plays little role in the generation of phasic bradycardiac responses to stimulation in fetal organisms. Cardiosomatic coupling is pronounced in young infants, but dissipates with age (Berntson \& Boysen, 1990; Hayne et al., 1991; Morrongiello \& Clifton, 1984). Hayne et al. (1991) observed that HR responses of young (6-day-old) rats are masked by motoric activity, as evidenced by the finding that HR responses to stimulation emerged following administration of the motor inhibitor, haloperidol. These investigators did not observe HR change to an olfactory stimulus in 1-day-old rat pups. They suggest two possible explanations for this result: (1) that the particular stimulus employed was not detected by newborns, or (2) that newborns' HR re- sponses were masked by sniffing, a behavior that was not eliminated by haloperidol administration. It is clear that perinatal rats are capable of concommitant HR and behavioral responses to stimulation. We previously reported HR and behavioral responses in perinatal rats to intraoral infusions of lemon (Ronca \& Alberts, 1990; Smotherman et al., 1991) and to gentle brush stroking (Ronca, Smotherman, Robinson, \& Alberts, 1987). In the present investigation, we uncovered no relationship between HR and behavioral responses to stimulation. These results suggest the possibility that cardiosomatic coupling originates after birth.

\section{Speculation on the Functional Importance of Perinatal Stimulation}

The present results provide direct evidence for fetal experience as a potential epigenetic mechanism that can play a role in regulating developmental processes. Early sensory experience is fundamental to the development of sensory systems and behavior. Formative effects of stimulation on the development of behavior and function are well documented. Premature sensory experience can influence perceptual development (Kenny \& Turkewitz, 1986; Lickliter, 1993). Reductions in embryonic limb movements, even for a relatively brief period, can permanently block the joint flexibility-that is, limb movements are part of the formative process of the musculoskeletal apparatus (Drachman \& Sokolov, 1966; Moessinger, 1983). Similarly, manipulations that disrupt fetal swallowing or early respiratory movements have been directly associated with impairments in gastrointestinal and pulmonary development (Liggins, 1982). The present results, along with those of several other studies (e.g., Smotherman \& Robinson, 1988), demonstrate that fetal sensations instigate fetal movements, thus suggesting that the onset or maintenance of developmentally adaptive movements are regulated by fetal experiences. There is similar evidence for experiential involvement in the development of neural (Weisel \& Hubel, 1963) architecture and function, as evidenced by the role of fetal experiences in promoting successful fetal adjustments to the postnatal niche. In particular, we have found evidence for fetal experiences facilitating the onset of pulmonary respiration in the newborn (Ronca \& Alberts, 1994). Other investigators have described a sequence of physiological events, involving changes in lung histology, adrenal responsivity, and CNS protections against hypoxia (Lagercrantz \& Slotkin, 1986), which we have suggested may be regulated by fetal experience (Ronca \& Alberts, in press).

Regardless of the precise mechanisms that are to be identified as sensory-mediated factors, the present data provide a useful foundation for the analysis of how the in-utero experience of the mammalian fetus can affect function and thus contribute directly and necessarily to developmental processes. 


\section{REFERENCES}

ADOLPH, E. F. (1967). Ranges of heart rates and their regulations at various ages (rat). American Journal of Physiology, 212, 595-602.

ADOLPH, E. F. (1971). Ontogeny of heart rate controls in hamster, rat and guinea pig. American Journal of Physiology, 220, 1896-1902.

ALBerTs, J. R. (1984). Sensory-perceptual development in the Norway rat: A view toward comparative studies. In R. Kail \& N. S. Spear (Eds.), Comparative perspectives on memory development (pp. 65101). Hillsdale, NJ: Erlbaum.

AlBerTs, J. R., \& RonCA, A. E. (1993). Fetal experience revealed by rats: Psychobiological insights. Early Human Development, 35, 153-166.

AlberTs, J. R., RonCA, A. E., \& BlumberG, M. S. (1992, November). Thermal imaging rat pups upon delivery into the nest. Paper presented at the International Society for Developmental Psychobiology, New Orleans.

Armitage, S. E., Baldwin, B. A., \& Vince, M. A. (1980). The fetal sound environment of sheep. Science, 208, 1173-1174.

BERG, K. M., \& SMITH, M. (1983). Behavioral thresholds for tones during infancy. Journal of Experimental Child Psychology, 35, 409-415.

Berg, W. K., \& Berg, K. M. (1979). Psychophysiological development in infancy: State, sensory function, and attention. In J. Osofsky (Ed.), Handbook of infant development (pp. 283-343). New York: Wiley.

BERNTSON, G. G. (1990). Heart system Vol. 6.0 [Computer program]. Columbus, $\mathrm{OH}$ : Ohio State University.

BERNTSON, G. G., \& Boysen, S. T. (1990). Cardiac indices of attention in infants, children and chimpanzees. In C. Rovee-Collier \& L. P. Lipsett (Eds.), Advances in infancy research (Vol. 6, pp. 187-220). Norwood, NJ: Ablex.

Berntson, G. G., Boysen, S. T., \& CACloppo, J. T. (1992). Cardiac orienting and defensive responses: Potential origins in autonomic space. In B. A. Campbell, H. Hayne, \& R. Richardson (Eds.), Attention and information processing in infants and adults: Perspectives from human and animal research (pp. 163-200). Hillsdale, NJ: Erlbaum.

Berntson, G. G., Tuber, D. S., Ronca, A. E., \& Bachman, D. S (1983). The decerebrate human: Associative learning. Experimental Neurology, 81, 77-88.

Bradley, R. M., \& Mistretta, C. M. (1975). Fetal sensory receptors. Physiological Reviews, 55, 352-382.

Campbell, B. A., Hayne, H., \& Richardson, R. (Eds.) (1992). Attention and information processing in infants and adults: Perspectives from human and animal research. Hillsdale, $\mathrm{NJ}$ : Erlbaum.

CoRNer, M. A. (1977). Sleep and the beginnings of behavior in the animal kingdom: Studies of early ultradian motility cycles in early life. Progress in Neurobiology, 8, 279-295.

COREY, E. L. (1934). Observations on cardiac activity in the fetal rat. Journal of Experimental Zoology, 72, 127-145.

DAWES, G. S. (1968). Fetal and neonatal physiology. Chicago: Year Book Medical.

DECASPER, A. J., \& FIFER, W .P. (1980). Of human bonding: Newborns prefer their mothers' voices. Science, 208, 1174-1176.

DECASPER, A. J., \& SPENCE, M. (1986). Newborns prefer a familiar story over an unfamiliar one. Infant Behavior \& Development, 9, 133-150.

Dollinger, M. J., Holloway, W. R., \& DenenberG, V. H. (1980). Parturition in the rat (Rattus norvegicus): Normative aspects and the temporal patterning of behavior. Behavioral Processes, 5, 21-37.

DRACHMAN, D. B., \& Sokolov, L. (1966). The role of movement in embryonic joint development. Developmental Biology, 14, 401-420.

FIFER, W. P., \& Moon, C. (1988). Auditory experience in the fetus. In W. P. Smotherman \& S. R. Robinson (Eds.), Behavior of the fetus (pp. 175-190). Caldwell, NJ: Telford.

Fuchs, A. R. (1969). Uterine activity in late pregnancy and during parturition in the rat. Biology of Reproduction, 1, 344-353.

Fuchs, A. R. (1978). Hormonal control of myometrial function during pregnancy and parturition. Acta Endocrinologica, 89 (Suppl. 221), 1-70.

Gerhardt, K. J., Abrams, R. M., \& Oliver, C. C. (1990). Sound environment of the fetal sheep. American Journal of Obstetrics \& Gynecology, 162, 282-287.
Goss, C. M. (1938). The first contractions of the heart in rat embryos. Anatomical Record, 70, 505-524.

GotTlieb, G. (1968). Prenatal behavior of birds. Quarterly Review of Biology, 43, 148-174.

GotTLIEB, G. (1971). Ontogenesis of sensory function in birds and mammals. In E. Tobach, L. R. Aronson, \& E. Shaw (Eds.), The biopsychology of development (pp. 67-128). New York: Academic Press.

GotTlieb, G. (1987). Development of species identification in ducklings: XIII. A comparison of malleable and critidal periods of perceptual development. Developmental Psychobiology, 20, 393-423.

GotTlieb, G. (1988). Development of species identification in ducklings: XV. Individual auditory recognition. Developmental Psychobiology, 21, 509-522.

GrahaM, F. K. (1992). Attention: The heartbeat, the blink, and the brain. In B. A. Campbell, H. Hayne, \& R. Richardson (Eds.), Attention and information processing in infants and adults: Perspectives from human and animal research (pp. 3-29). Hillsdale, NJ: Erlbaum.

Graham, F. K., Anthony, B. J., \& Ziegler, B. L. (1983). The orienting response and developmental processes. In D. A. T. Siddle (Ed.), Orienting and habituation: Perspectives in human research (pp. 371-430). Chichester, U.K.: Wiley.

GrahAM, F. K., \& JACKSON, J. C. (1970). Arousal systems and infant heart rate responses. In H. W. Reese \& L. P. Lipsett (Eds.), Advances in child development and behavior (Vol. 5, pp. 59-117). New York: Academic Press.

Hall, W. G., \& Oppenheim, R. W. (1987). Developmental psychobiology: Prenatal, perinatal, and early postnatal aspects of behavioral development. Annual Review of Psychology, 38, 91-128.

Haroutunian, V., \& CAMPbell, B. A. (1981). Development and habituation of the heart rate orienting response to auditory and visual stimuli in the rat. Journal of Comparative \& Physiological Psychology, 95, 166-174.

Haroutunian, V., \& Campbell, B. A. (1982). Neural control of the heart-rate-orienting response in preweanling rats. Behavioral \& Neural Biology, 36, 24-39.

Hayne, H., Richardson, R., \& Campbell, B. A. (1991). Developmental constraints on the expression of behavioral and heart-rate orienting responses: I. The role of cardiosomatic coupling. Developmental Psychobiology, 24, 1-18.

Hayne, H., Richardson, R., \& Campbell, B. A. (1992). Developmental constraints on the expression of behavioral and heart-rate orienting responses: II. The role of ambient temperature. Developmental Psychobiology, 25, 51-66.

HiguchI, T., Uchide, K., Honda, K., \& Negoro, H. (1987). Pelvic neurectomy abolishes the fetus-expulsion reflex and induces dystocia in the rat. Experimental Neurology, 96, 443-455.

Hofer, M. A., \& REISER, M. F. (1969). The development of cardiac rate regulation in preweanling rats. Psychosomatic Medicine, 31, 372-388.

JaCQUes, S. L., WEAVER, D. R., \& RePPERT, S. M. (1987a). Penetration of light into the uterus of pregnant mammals. Photochemistry \& Photobiology, 45, 637-641.

Jacques, S. L., Weaver, D. R., \& RePPeRT, S. M. (1987b). Precocious spiny mice as a model to assess the potential for retina-mediated light perception in utero. Society for Neuroscience Abstracts, 13, 864.

KENNY, P. A., \& TURKEWITZ, G. (1986). Effects of unusually early visual stimulation on the development of homing behavior in the rat pup. Developmental Psychobiology, 19, 57-66.

KIRBY, R. F., \& MCCARTY, R. (1987). Ontogeny of functional innervation to the heart and adrenal medulla in the preweanling rat. Journal of the Autonomic Nervous System, 19, 67-75.

Kuo, Z. Y. (1967). The dynamics of behavior development: An epigenetic view. New York: Random House.

Lagercrantz, H., \& Slotkin, T. A. (1986). The "stress" of being born. Scientific American, 254, 100-107.

LANE, H. H. (1917). The correlation between structure and function in the development of the special senses of the white rat. University of Oklahoma Bulletin, New Series 140, University Studies, 8, 1-88.

LaRson, S. K., \& PoRgES, S. W. (1982). The ontogeny of heart period patterning in the rat. Developmental Psychobiology, 15, 519-528. Lecanuet, J.-P., Granier-Deferre, C., Cohen, H., Le Houezec, R., \& BUSNEL, M.-C. (1986). Fetal responses to acoustic stimulation de- 
pend on heart rate variability pattern, stimulus intensity and repetition. Early Human Development, 13, 269-283.

LICKLITER, R. (1993). Timing and the development of perinatal perceptual organization. In G. Turkewitz \& D. A. Devenny (Eds.), Developmental time and timing (pp. 105-123). Hillsdale, $\mathrm{NJ}$ : Erlbaum.

LigGins, G. C. (1982). The fetus and birth. In C. R. Austin \& R. V. Short (Eds.), Reproduction in mammals: Book 2. Embryonic and fetal development. New York: Cambridge University Press.

MARTIN, L. T., \& ALBERTS, J. R. (1982). Associative learning in neonatal rats revealed by heart rate response patterns. Journal of Comparative \& Physiological Psychology, 96, 668-675.

MiLLS, E. (1975). Time course for development of vagal inhibition of the heart in neonatal rats. Life Sciences, 23, 2717-2720.

MoEssinger, A. C. (1983). Fetal akinesia deformation sequence: An animal model. Pediatrics, 72, 857-863.

Morrongiello, B. A., \& Clifton, R. K. (1984). Effects of sound frequency on behavioral and cardiac orienting in newborn and fivemonth-old infants. Journal of Experimental Child Psychology, 38 , 429-446.

MountCastle, V. B. (1974). Medical physiology (Vol. 2). St. Louis: C. V. Mosby.

Narayanan, C. H., Fox, M. W., \& Hamburger, V. (1971). Prenatal development of spontaneous and evoked activity in the rat. Behavior, 40, 100-134.

Nathanielsz, P. W., Figueroa, J. P., El Badry, A., Sunderi, S., Frank, D. A., Pimentel, G., Poore, E. R., \& Mitchell, M. D. (1985). Myometrial activity: Controls and effects. In C. T. Jones \& P. W. Nathanielsz (Eds.), The physiological development of the fetus and newborn. London: Academic Press.

OBRIST, P. A. (1981). Cardiovascular psychophysiology: A perspective. New York: Plenum.

OPPENHEIM, R. W. (1972). An experimental investigation of the possible role of tactile and proprioceptive stimulation in certain aspects of embryonic behavior in the chick. Developmental Psychobiology, 5, 71-91.

Pavlov, I. P. (1927). Conditioned reflexes (G. V. Anrep, Trans.). London: Oxford University Press.

Pederson, P. E., \& Blass, E. M. (1982). Prenatal and postnatal determinants of the first suckling episode in albino rats. Developmental Psychobiology, 15, 349-355.

Preuss, K. C., \& Weitman, S. D. (1987). Determination of in-utero fetal rat heart rate by ultrasound. Journal of Pharmacology Methods, 17, 59-65.

Previc, F. (1991). A general theory concerning the prenatal origins of cerebral lateralization in humans. Psychological Review, 98, 299334.

REYNOLDS, S. R. M. (1962). Fetal sensory deprivation: A problem of adaptation to the uterine environment. American Journal of Obstetrics \& Gynecology, 83, 800-808.

RonCA, A. E., \& AlberTs, J. R. (1990). Heart rate development and sensory-evoked cardiac responses in perinatal rats. Physiology \& Behavior, 47, 1075-1082.

RonCA, A. E., \& ALBERTs, J. R. (1993). [Videographic analysis of pupdirected licking by rat dams during parturition]. Unpublished raw data.

RoNCA, A. E., \& AlBERTs, J. R. (1994). Simulated uterine contractions facilitate fetal and newborn respiratory behavior in rats. Manuscript submitted for publication.

RonCA, A. E., \& ALBERTS, J. R. (in press). Maternal contributions to fetal experience and the transition from prenatal to postnatal life. In J.-P. Lecanuet, W. Fifer, W. P. Smotherman, \& N. A. Krasnegor (Eds.), Fetal development: A psychobiological perspective. Hillsdale, NJ: Erlbaum.

Ronca, A. E., Berntson, G. G., \& Tuber, D. S. (1985). Cardiac orienting and habituation to auditory and vibrotactile stimuli in the infant decerebrate rat. Developmental Psychobiology, 18, 79-83.

Ronca, A.E., Kamm, K., Thelen, E., \& Alberts, J.R. (1994). Proximal control of fetal rat behavior. Developmental Psychobiology, 27, 23-38.
Ronca, A. E., Lamkin, C. A., \& Alberts, J. R. (1993). Maternal contributions to sensory experience in the fetal and newborn rat (Rattus norvegicus). Journal of Comparative Psychology, 107, 61-74.

Ronca, A. E., Smotherman, W. P., Robinson, S. R., \& Alberts, J. R. (1987, November). Chemosensory and tactile stimuli elicit heart rate and motor responses in the rat fetus. Paper presented at the International Society for Developmental Psychobiology, New Orleans.

RosenblatT, J. S., \& Lehrman, D. S. (1963). Maternal behavior in the laboratory rat. In H. L. Reingold (Ed.), Maternal behavior in mammals (pp. 8-57). New York: Wiley.

SChaAl, B., Orgeur, P., \& Rognon, C. (in press). Odor sensing in the human fetus: Anatomical, functional and chemoecological bases. In J.-P. Lecanuet, W. Fifer, W. P. Smotherman, \& N. A. Krasnegor (Eds.), Fetal development: A psychobiological perspective. Hillsdale, NJ: Erlbaum.

SeIdLeR, F. J., \& SLotkin, T. A. (1979). Presynaptic and postsynaptic contributions to ontogeny of sympathetic control of heart rate in the preweanling rat. British Journal of Pharmacology, 65, 431434.

Smotherman, W. P., \& Robinson, S. R. (1986). Environmental determinants of behavior in the rat fetus. Animal Behaviour, 34, 18591873.

Smotherman, W. P., \& Robinson, S. R. (1987). Prenatal expression of species-typical action patterns in the rat fetus (Rattus norvegicus). Journal of Comparative Psychology, 101, 190-196.

Smotherman, W. P., \& Robinson, S. R. (1988). Behavior of rat fetuses following chemical or tactile stimulation. Behavioral Neuroscience, 102, 24-34.

Smotherman, W. P., Robinson, S. R., Ronca, A. E., Alberts, J. R., \& HePper, P. (1991). Heart rate responses of the rat fetus and neonate to a chemosensory stimulus. Physiology \& Behavior, 50, 47-52.

SoKolov, Y. N. (1963). Perception and the conditioned reflex. New York: Pergamon.

TAM, P. P. L., \& CHAN, S. T. H. (1977). Changes in the composition of maternal plasma, fetal plasma and fetal extraembryonic fluid during gestation in the rat. Journal of Reproduction \& Fertility, 51, 41-51.

TUCKER, D. C. (1985). Components of functional sympathetic control of heart rate in neonatal rats. American Journal of Physiology, 248, R601-R610.

VINCE, M. A. (1979). Postnatal effects of prenatal sound stimulation in the guinea pig. Animal Behavior, 27, 908-918.

Vince, M. A., Armitage, S. E., Baldwin, B. A., Toner, J. N., \& Moore, B. C. (1982). The sound environment of the foetal sheep. Behavior, 81, 296-315.

Vince, M. A., Armitage, S. E., Shillito-Walser, E. S., \& Reader, M. (1982). Postnatal consequences of prenatal sound stimulation in the sheep. Behavior, 81, 128-139.

Vince, M. A., Billing, B. A., Baldwin, B. A., Toner, J. N., \& WELLER, C. (1985). Maternal vocalisations and other sound in the fetal lamb's sound environment. Early Human Development, 11 , 179-190.

Vince, M. A., Lynch, J. J., Mottershead, B. E., Green, G., \& ELWIN, R. (1985). Sensory factors involved in immediately postnatal ewe/lamb bonding. Behavior, 90, 60-84.

WALKER, D., GRIMWADE, J., \& WoOD, C. (1971). Intrauterine noise: A component of the fetal environment. American Journal of Obstetrics \& Gynecology, 109, 91-95.

WeisEL, T. N., \& HUBEL, D. H. (1963). Single-cell responses in striate cortex of kittens deprived of vision in one eye. Journal of Neurophysiology, 26, 1003-1017.

WEKSTEIN, D. R. (1965). Heart rate of the preweanling rat and its autonomic control. American Journal of Physiology, 208, 1259-1262.

(Manuscript received November 18, 1993; revision accepted for publication September 15, 1994.) 